\section{Ultrasonographic features of pure ductal carcinoma in situ of the breast: correlations with pathologic features and biological markers}

\author{
Hwajin Cha', Yun-Woo Chang', Eun Ji Lee', Ji Young Hwang', Hyun Joo Kim', \\ Eun Hye Lee ${ }^{2}$, Jung Kyu Ryu ${ }^{3}$ \\ ${ }^{1}$ Department of Radiology, Soonchunhyang University Seoul Hospital, Seoul; ${ }^{2}$ Department \\ of Radiology, Soonchunhyang University Bucheon Hospital, Bucheon; ${ }^{3}$ Department of \\ Radiology, Kyung Hee University Hospital at Gangdong, Seoul, Korea
}

Purpose: The purpose of this study was to evaluate the ultrasonographic features of pure ductal carcinoma in situ (DCIS) of the breast and to evaluate the correlations of ultrasonographic features with pathologic and biological features.

Methods: A total of 141 lesions in 138 women with pure DCIS who underwent preoperative breast ultrasonography were retrospectively reviewed. Ultrasonographic features were analyzed using the American College of Radiology Breast Imaging Reporting and Data System (BIRADS) ultrasonography lexicon and the diagnostic criteria of the Japan Society of Ultrasonics in Medicine. Pathologic features including the nuclear grade and presence of comedonecrosis were evaluated. Biological markers including estrogen receptor, progesterone receptor, and human epidermal growth factor receptor 2 (HER2) status, as well as the Ki-67 index, were recorded. Ultrasonographic features were compared with pathologic findings and biological markers using the chi-square test. P-values of $<0.05$ were considered to indicate statistical significance.

Results: Of the 141 lesions, 75 (53.2\%) were mass lesions, 56 (39.7\%) were non-mass lesions, and $10(7.1 \%)$ were not visible. The most common feature of the mass pattern was a mass with irregular shape (32.6\%), an indistinct margin (27.7\%), and hypoechogenicity (37.6\%). Microcalcifications were observed in 48 cases (36.6\%) as an associated feature. Calcifications outside of a mass were more common than calcifications within a mass. Ultrasonographic microcalcifications and ductal changes were frequently observed in non-mass lesions. Ultrasonographic non-mass lesions were associated with high-grade DCIS $(P=0.004)$ and the presence of comedonecrosis $(P=0.006)$. Microcalcifications were significantly associated with high-grade DCIS $(P<0.001)$, the presence of comedonecrosis $(P<0.001)$, an elevated Ki-67 $(P<0.001)$, and HER2 positivity $(P=0.003)$.

Conclusion: The most common ultrasonographic feature of pure DCIS was an irregular, hypoechoic mass with an indistinct margin. Ultrasonographic microcalcifications and ductal changes were more frequent in non-mass lesions, which were correlated with poor prognostic factors, such as a high nuclear grade, comedonecrosis, HER2 positivity, and an elevated Ki-67 index.

Keywords: Breast; Ductal carcinoma in situ; Ultrasonography; Pathology; Biological markers

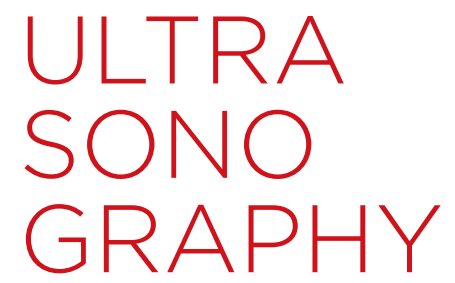

ORIGINAL ARTICLE

https://doi.org/10.14366/usg. 17039 pISSN: 2288-5919 - elSSN: 2288-5943 Ultrasonography 2018;37:307-314

Received: May 18, 2017 Revised: October 10, 2017 Accepted: October 13, 2017

Correspondence to: Yun-Woo Chang, MD, Department of Radiology, Soonchunhyang University Seoul Hospital, 59 Dasakwan-ro, Yongsan-gu, Seoul 04401, Korea

Tel. +82-2-709-9396

Fax. +82-2-709-3928

E-mail: ywchang@schmc.ac.kr

This is an Open Access article distributed under the terms of the Creative Commons Attribution NonCommercial License (http://creativecommons.org/ licenses/by-nc/3.0/) which permits unrestricted noncommercial use, distribution, and reproduction in any medium, provided the original work is properly cited.

Copyright (C) 2018 Korean Society of Ultrasound in Medicine (KSUM)

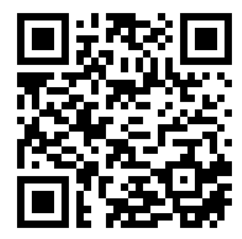

How to cite this article:

Cha H, Chang YW, Lee EJ, Hwang JY, Kim HJ, Lee $\mathrm{EH}$, et al. Ultrasonographic features of pure ductal carcinoma in situ of the breast: correlations with pathologic features and biological markers. Ultrasonography. 2018 0ct;37(4):307-314. 


\section{Introduction}

Ductal carcinoma in situ (DCIS) is defined as a malignant proliferation of epithelial cells confined to endothelial lobular units without invading the basement membrane [1]. The prevalence of DCIS has increased with the widespread practice of breast screening through mammography. In the United States, the prevalence of DCIS was 1.87 per 100,000 in the 1970 s before mammography screening programs, accounting for less than $5 \%$ of all breast cancers. However, the prevalence increased to 32.5 per 100,000 in 2004 [2-5]. Although DCIS accounts for more than $20 \%$ of breast cancers diagnosed in the United States, the assumption that all cases of DCIS are precursor lesions of invasive breast cancer has been questioned in recent years [6-8].

The most common finding of DCIS is the presence of microcalcifications in the mammography screening of asymptomatic patients $[2,9]$. Breast ultrasonography is considered to be an adjunct to screening mammography, although breast ultrasonography is superior to mammography in detecting lesions in patients with symptomatic DCIS [10]. The most common ultrasonographic findings of DCIS are a hypoechoic mass with an irregular shape and indistinct margin $[11,12]$. Additional findings include microcalcifications, ductal changes, or structural distortions [11-18].

Even though it is impossible to predict with certainty whether DCIS will progress to invasive disease, histologic features classified according to the microscopic findings of DCIS provide important information on its prognosis. It has been reported that a high nuclear grade, a solid or cribriform architectural pattern, and comedonecrosis are associated with a high recurrence rate when conservative treatment is performed $[5,19,20]$. Biological markers can also provide information useful for predicting the biological response, pathologic progression, treatment response, and tumor recurrence in patients with DCIS $[21,22]$. The estrogen receptor (ER), progesterone receptor (PR), human epidermal growth factor receptor 2 (HER2), and the Ki-67 index are the most studied biological markers. They have been routinely measured to predict the risk associated with DCIS $[21,23,24]$. When DCIS develops into invasive breast cancer, ER and HER2 status and the breast cancer subtype are usually maintained $[6,25]$.

To date, some studies have presented the ultrasonographic features of pure DCIS, but few studies have reported comparisons between the ultrasonographic findings and pathologic features of pure DCIS $[10,12,14,15,17,23,26]$. The evaluation of ultrasonographic features in correlation with the pathologic and biological features of DCIS will provide valuable clues to predict the prognosis of the disease, and the purpose of this study was therefore to evaluate the ultrasonographic features of pure DCIS and to investigate the correlations of ultrasonographic features with pathologic and biological features.

\section{Materials and Methods}

\section{Patients}

This retrospective study was approved by the Institutional Review Board of our institution for patients' record and consent to use of information. From December 2003 to April 2016, 178 patients were diagnosed with pure DCIS based on pathologic findings. Thirty-two patients who did not undergo ultrasonography before excisional biopsy and five patients who had no history of surgical biopsy were excluded from this study, as well as three patients without mammograms were also excluded. Of the remaining 138 patients who were diagnosed with pure DCIS, 3 had bilateral lesions. Ultimately, 141 ultrasonographic findings in 138 women (mean, 51.3 years; range, 28 to 83 years) were included in our study for the evaluation of the imaging features of pure DCIS (Fig. 1) and the investigation of correlations with pathologic features and prognostic biomarkers (Fig. 1). Sixty-four patients (46\%) were symptomatic. Of the symptomatic cases, 47 had palpable masses, 12 had discharge, three had pain, and two had nipple eczema.

\section{Ultrasonographic Analysis}

Ultrasonography was performed by a breast radiologist using a broad-band 5-12 MHz linear array transducer (LOGIQ E9, GE, Wauwatosa, WI, USA) or a broad-band 5-17 MHz linear array transducer (iU 22, Philips, Seattle, WA, USA). Ultrasonography was performed on both breasts according to our hospital's basic screening method. Two orthogonal images and color Doppler images were obtained on the axial and vertical planes when the lesion was

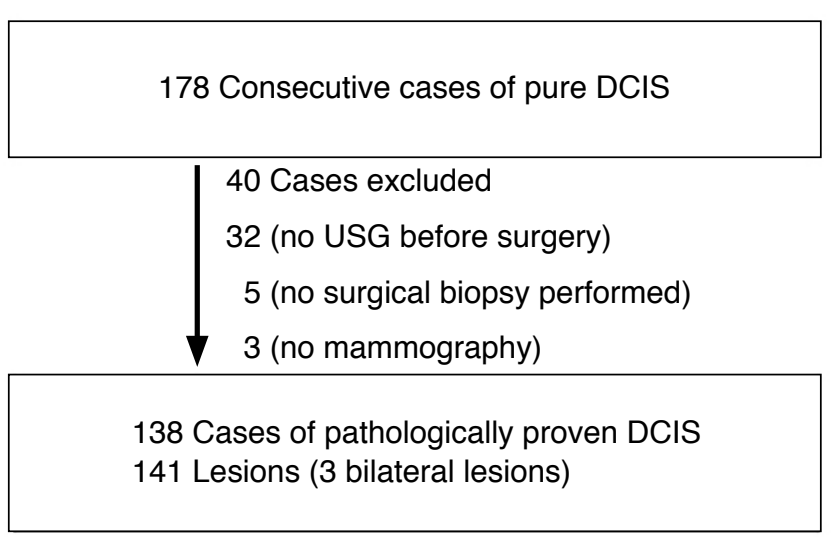

Fig. 1. Inclusion and exclusion criteria. DCIS, ductal carcinoma in situ; USG, ultrasonography. 
seen. Additional images were obtained based on the radiologist's decision. The ultrasonographic findings were analyzed by consensus by breast imaging specialists who had 14 years of experience in breast imaging, along with one resident who had been trained for more than 5 months, using a picture archiving and communication system monitor. Lesions were analyzed using the terms of the American College of Radiology Breast Imaging Reporting and Data System (BI-RADS) lexicon [27]. In addition, to describe lesions that were difficult to define as mass lesions on the ultrasonographic findings of DCIS, the lesion pattern was classified as a mass lesion, non-mass lesion, or ultrasonographic occult lesion based on the guidelines of the Japan Society of Ultrasonics in Medicine [28]. Mass lesions were defined as lesions for which the mass was different from the surrounding tissue and constituents. Non-mass lesions were defined as lesions that were difficult to diagnose as a mass. The size, shape, margin, echo pattern, orientation, and color Doppler images of mass lesions were analyzed. Echogenic foci suspected of microcalcifications on ultrasonography were considered positive only when corresponding microcalcifications were seen on mammography. Ultrasonographic ductal changes were considered to be present when there was a cystic dilatation of an irregular duct branching from malignant lesions, intraductal masses, or debris. The presence of architectural distortion accompanying the lesion was also analyzed.

\section{Histopathologic Analysis}

Pathologic specimens were analyzed by a pathologist with more than 10 years of experience. The nuclear grade was classified as low, intermediate, or high based on the Van Nuys classification. The presence of comedonecrosis was also analyzed. Immunohistochemical analysis was performed for ER, PR, HER2, and the Ki-67 index. ER and PR positivity was defined as nuclear staining of at least $1 \%$ positive tumor nuclei [29]. HER2 was scored as 0 (no staining), 1+ (weak and incomplete membrane staining), $2+$ (strong, complete membrane staining in $\leq 30 \%$ of tumor cells or weak/moderate heterogeneous complete staining in $\geq 10 \%$ ), or $3+$ (strong, complete membrane staining in $>30 \%$ of tumor cells) through an immunohistochemical analysis [30]. We performed silver-enhanced in situ hybridization (ISH) for all equivocal cases (2+ immunohistochemical staining) using the Inform HER2 Dual ISH DNA probe cocktail (Ventana Medical Systems Inc., Tucson, $A Z$, USA) to evaluate HER2 expression using a standard method. The Ki-67 index was determined as the percentage of tumor cells that exhibited nuclear staining. The Ki-67 index was divided into low-grade $(<5 \%)$, intermediate-grade $(6 \%-19 \%)$, and high-grade $(\geq 20 \%)$ based on the rate of positive nuclear staining of cancer cells, following previously established guidelines [31,32].

\section{Statistical Analysis}

Statistical analysis was performed by dividing the lesions into mass lesions and non-mass lesions. The frequency of various factors according to the lesion type was evaluated. Ultrasonographic findings were compared with pathologic findings (nuclear grade and presence of comedonecrosis) and biological factors according to the presence of microcalcifications and ductal changes. As the comparative analysis variables showed a normal distribution, a parametric analysis method (the chi-square test) was used. P-values $<0.05$ were considered to indicate statistical significance. Statistical analysis was performed using SPSS software ver. 20.0 (IBM Corp., Armonk, NY, USA).

\section{Results}

\section{Ultrasonographic Features of Pure DCIS}

Regarding ultrasonographic findings, mass lesions were found in 75 cases (53.2\%) (Fig. 2), non-mass lesions in 56 cases (39.7\%) (Fig. 3), and ultrasonographic occult lesions in 10 cases (7.1\%). The most common shape of pure DCIS was irregular (46 cases, $32.6 \%$ ). In addition, 18 cases (12.8\%) were oval and 11 (7.8\%) were round. Fifty-seven cases (40.4\%) showed a non-circumscribed margin, while only 18 (12.8\%) showed a circumscribed margin and $39(27.7 \%)$ had an indistinct margin. Hypoechogenicity was the

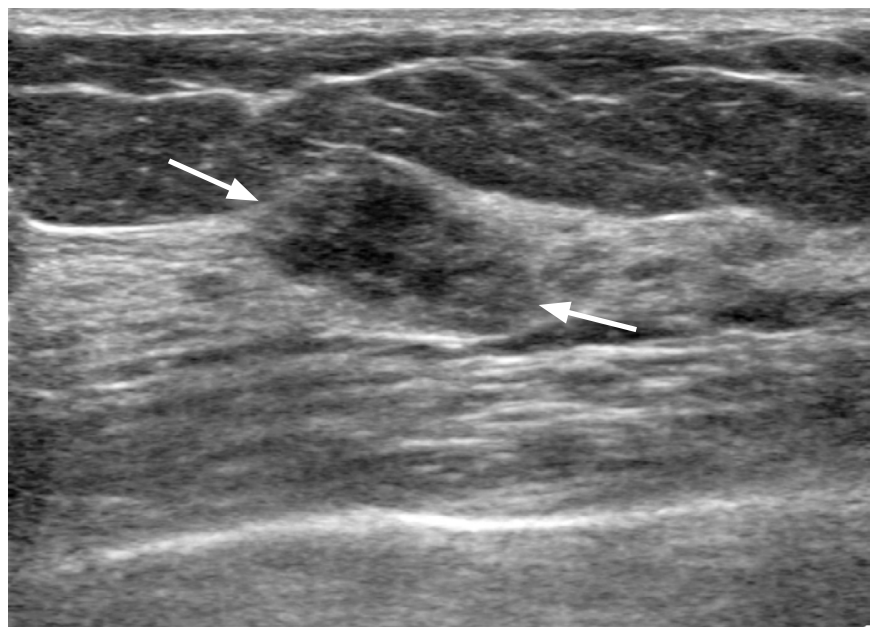

Fig. 2. A 62-year-old woman in whom ductal carcinoma in situ (DCIS) was incidentally detected in a screening examination. An irregular shape, indistinct margin, and hypoechoic mass (arrows) were noted in the left breast on ultrasonography. No microcalcifications were present. After left partial mastectomy, noncomedonecrosis-type pure DCIS was confirmed. Both the estrogen and progesterone receptors were positive, and human epidermal growth factor receptor was negative on immunochemical staining. The Ki-67 index was less than $20 \%$. 
most common echo pattern (53 cases, 37.6\%). The orientation of the mass was non-parallel in 50 cases (35.5\%) and parallel in 25 $(17.7 \%)$. The average size of the mass lesions was $1.3 \mathrm{~cm}$ (range, 0.4 to $2.7 \mathrm{~cm}$ ), and that of the non-mass lesions was $2.0 \mathrm{~cm}$ (range, 1.2 to $5.3 \mathrm{~cm}$ ). Forty-eight cases $(36.6 \%)$ showed microcalcifications and $21(16.0 \%)$ showed ductal changes, which were more frequently observed in non-mass lesions (Fig. 4). Six cases (4.6\%) of non-mass lesions with architectural distortion were also found. Color Doppler examination data were available for 108 cases,

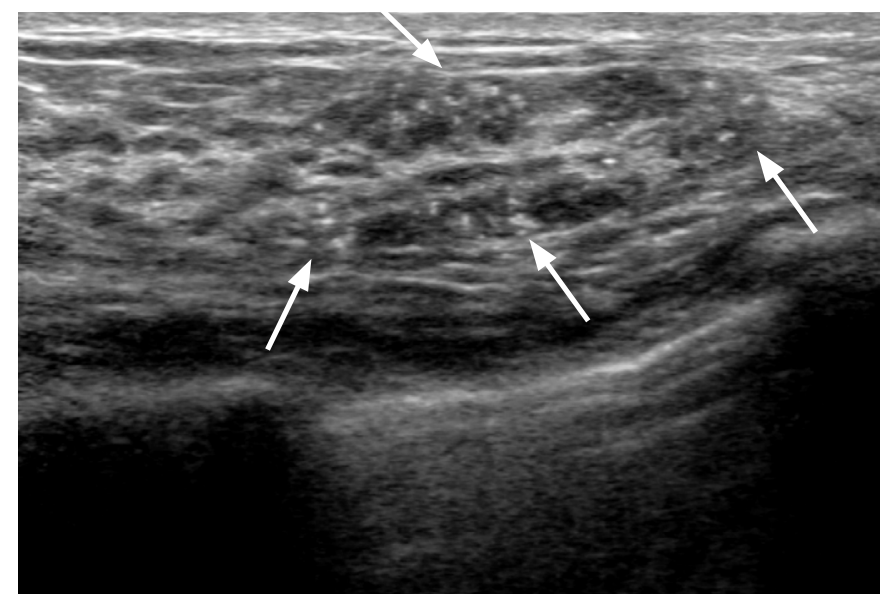

A

Fig. 3. A 41-year-old woman with ductal carcinoma in situ.

A, B. Ultrasonography shows a hypoechoic non-mass lesion with microcalcifications outside of the mass (arrows) with increased vascularity. Pathology revealed a high nuclear grade, estrogen and progesterone receptor negativity, human epidermal growth factor receptor positivity, and a Ki-67 index of $20 \%$.

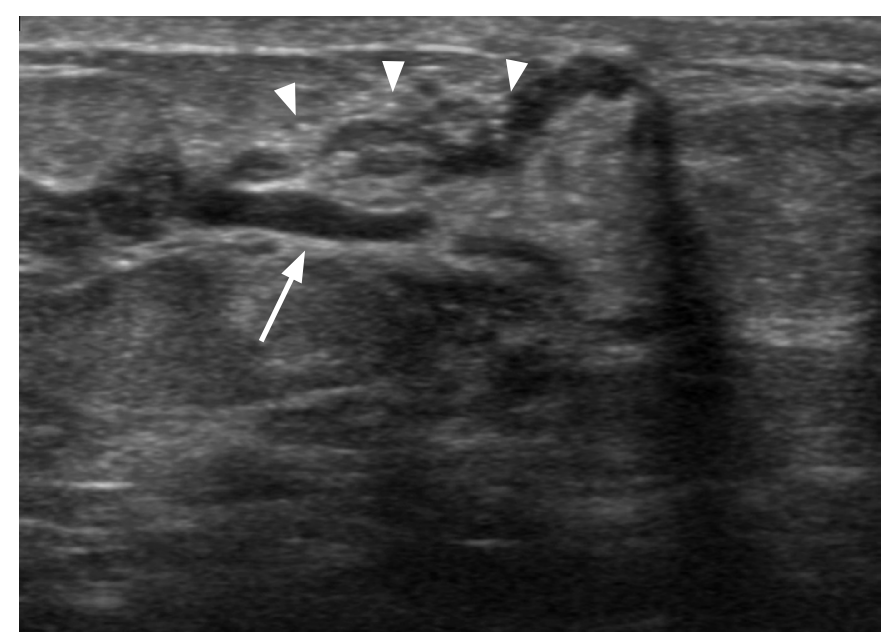

A

Fig. 4. A 54-year-old woman with left breast pain and bloody nipple discharge.

A. Ultrasonography demonstrates localized ductal dilatation (arrow) with microcalcifications of a non-mass lesion (arrowheads). B. Increased vascularization was noted on color Doppler ultrasonography. Pathology revealed a high nuclear grade and comedonecrosis. The estrogen receptor and human epidermal growth factor receptor were positive, the progesterone receptor was negative, and the Ki-67 index was more than $20 \%$ on immunochemical staining. 
Table 1. Ultrasonographic morphologic distribution of pure DCIS lesions

\begin{tabular}{|c|c|}
\hline Morphologic classification & No. of lesions $(n=141)$ \\
\hline \multicolumn{2}{|l|}{ Pattern of lesion } \\
\hline Mass & $75(53.2)$ \\
\hline \multicolumn{2}{|l|}{ Shape } \\
\hline Oval & $18(12.8)$ \\
\hline Round & $11(7.8)$ \\
\hline Irregular & $46(32.6)$ \\
\hline \multicolumn{2}{|l|}{ Margin } \\
\hline Circumscribed & $18(12.8)$ \\
\hline Not circumscribed & $57(40.4)$ \\
\hline Indistinct & $39(27.7)$ \\
\hline Microlobulated & $15(10.6)$ \\
\hline Angular & $2(1.4)$ \\
\hline Spiculated & $1(0.7)$ \\
\hline \multicolumn{2}{|l|}{ Echo pattern } \\
\hline Isoechoic & $10(7.1)$ \\
\hline Hypoechoic & $53(37.6)$ \\
\hline Complex cystic and solid & $8(5.7)$ \\
\hline Heterogeneous & $4(2.8)$ \\
\hline \multicolumn{2}{|l|}{ Orientation } \\
\hline Parallel & $25(17.7)$ \\
\hline Nonparallel & $50(35.5)$ \\
\hline Non-mass & $56(39.7)$ \\
\hline Occult ${ }^{a)}$ & $10(7.1)$ \\
\hline Calcifications & $131(100)$ \\
\hline No microcalcifications & $83(63.4)$ \\
\hline Microcalcifications & 48 (36.6) \\
\hline Calcifications in a mass & $14(10.7)$ \\
\hline Calcifications outside of a mass & $29(22.1)$ \\
\hline Intraductal calcifications & $5(3.8)$ \\
\hline Ductal change & $131(100)$ \\
\hline Negative & $110(84.0)$ \\
\hline Positive & $21(16.0)$ \\
\hline Architectural change & $131(100)$ \\
\hline Negative & $125(95.4)$ \\
\hline Positive & $6(4.6)$ \\
\hline Vascularity & $108(100)$ \\
\hline Absent & $60(55.6)$ \\
\hline Increased vascularity & $48(44.4)$ \\
\hline
\end{tabular}

Values are presented as number (\%).

DCIS, ductal carcinoma in situ.

${ }^{a)}$ Ten lesions that were not visible on ultrasonography. ${ }^{b}$ Color Doppler was available for 108 cases. nuclear grade and comedonecrosis ( $\mathrm{P}<0.001$ for both) (Table 2 ).

When correlations between the characteristic findings of ultrasonography and biological markers were analyzed, the ultrasonographic presence of microcalcifications showed a statistically significant association with a $\mathrm{Ki}-67$ index higher than $20 \%(P<0.001)$ and HER2 positivity $(P=0.003)$ (Table 3$)$.

\section{Discussion}

The ultrasonographic findings of pure DCIS have been presented in several studies, and the findings of our study are similar to those of previous reports $[10-12,14-18,26]$. In our study, the most common ultrasonographic appearance of DCIS was a mass lesion. Approximately $53.2 \%$ of cases were irregular and hypoechoic masses without a circumscribed margin. Although these findings of DCIS were indistinguishable from those of invasive ductal carcinoma, our results are consistent with those of previous studies showing that the most common ultrasonographic finding of DCIS was a mass in approximately $52 \%-88 \%$ of cases $[10-12,14-18,26]$. Scoggins et al. [10] reported that a visible lesion on ultrasonography was present in $52 \%$ of 691 patients with pure DCIS and that $76 \%$ of those cases had mass lesions. Park et al. [12] analyzed 76 cases of pure DCIS (48 asymptomatic and 25 symptomatic), and found that $75 \%$ of the lesions were visible on ultrasonography. A morphologic analysis found that $50 \%$ of non-high-grade DCIS cases showed an irregular shape with an indistinct and microlobulated boundary and a hypoechoic mass. In our study, a lesion visible on ultrasonography was present in $92.9 \%$ of cases (131 of 141), which is higher than prior studies. The reason for the higher rate of lesion detection on ultrasonography in our study may have been related to the fact that $45.4 \%$ of the patients were symptomatic, in contrast to previous studies. In addition, this tendency might also be related to the fact that patients who had microcalcifications on mammography and underwent an excisional biopsy without ultrasonography may not have been included in our study.

In the present study, although the most common ultrasonographic finding of pure DCIS was a mass lesion, microcalcifications and ductal changes seen on ultrasonography were more common in non-mass lesions than in mass lesions. Ultrasonographic ductal abnormalities or dilatation is not a common finding in DCIS, and have been reported to be present in $4.6 \%-5 \%$ of cases $[12,15]$. In contrast, in our study, $16 \%$ of patients had ductal changes, which is a higher rate than has previously been reported. It has been suggested that dilatation of the duct might be due to necrosis in tumor cells, necrosis in the lumen of the duct, or a lymph-forming reaction around the duct [11].

In our study, microcalcifications on ultrasonography showed 
Table 2. Cross-tabulation of US findings of pure DCIS with pathologic findings

\begin{tabular}{|c|c|c|c|c|c|c|c|}
\hline \multirow{2}{*}{ US finding } & \multicolumn{3}{|c|}{ Nuclear grade } & \multirow{2}{*}{ P-value } & \multicolumn{2}{|c|}{ Comedonecrosis } & \multirow{2}{*}{ P-value } \\
\hline & Low $(n=39)$ & Intermediate $(n=34)$ & High $(n=50)$ & & None $(n=83)$ & Comedonecrosis $(n=48)$ & \\
\hline \multicolumn{8}{|l|}{ US pattern } \\
\hline Mass & $30(24.4)$ & $20(16.3)$ & $21(17.1)$ & 0.004 & $56(42.7)$ & $20(15.3)$ & 0.006 \\
\hline Non-mass & $9(7.3)$ & $14(11.4)$ & $29(23.6)$ & & $27(20.6)$ & $28(21.4)$ & \\
\hline \multicolumn{8}{|c|}{ US microcalcifications } \\
\hline Negative & $33(26.8)$ & $27(22.0)$ & $15(12.2)$ & $<0.001$ & $67(51.1)$ & $16(12.2)$ & $<0.001$ \\
\hline Positive & $6(4.9)$ & $7(5.7)$ & $35(28.5)$ & & $16(12.2)$ & $32(24.4)$ & \\
\hline \multicolumn{8}{|l|}{ US ductal change } \\
\hline Negative & $35(28.5)$ & $28(22.8)$ & $41(33.3)$ & 0.554 & $70(53.4)$ & $40(30.5)$ & 0.880 \\
\hline Positive & $4(3.3)$ & $6(4.9)$ & $9(7.3)$ & & $13(9.9)$ & $8(6.1)$ & \\
\hline
\end{tabular}

Values are presented as number (\%).

DCIS, ductal carcinoma in situ; US, ultrasonography.

Table 3. Cross-tabulation of US findings of pure DCIS with biological markers

\begin{tabular}{|c|c|c|c|c|c|c|c|c|c|c|c|c|c|}
\hline \multirow[b]{2}{*}{ US finding } & \multicolumn{2}{|c|}{$\operatorname{ER}(n=131)$} & \multirow{2}{*}{ P-value } & \multicolumn{2}{|c|}{$P R(n=131)$} & \multirow[b]{2}{*}{ P-value } & \multicolumn{2}{|c|}{ HER2 $(n=131)$} & \multirow[b]{2}{*}{ P-value } & \multicolumn{3}{|c|}{ Ki-67 $(n=121)$} & \multirow[b]{2}{*}{ P-value } \\
\hline & $-(n=41)$ & $+(n=90)$ & & $-(n=50)$ & $+(n=81)$ & & $-(n=61)$ & $+(n=70)$ & & $\begin{array}{c}<5 \% \\
(n=42)\end{array}$ & $\begin{array}{c}6 \%-20 \% \\
(n=44)\end{array}$ & $\begin{array}{l}>20 \% \\
(n=35)\end{array}$ & \\
\hline US pattern & & & 0.341 & & & 0.473 & & & 0.113 & & & & 0.110 \\
\hline Mass & $21(16.0)$ & $55(42.0)$ & & 27 (20.6) & $49(37.4)$ & & $40(30.5)$ & $36(27.5)$ & & $28(23.1)$ & $25(20.7)$ & $15(12.4)$ & \\
\hline Non-mass & $20(15.3)$ & $35(26.7)$ & & 23 (17.6) & $32(24.4)$ & & $21(16.0)$ & $34(26.0)$ & & $14(11.6)$ & $19(15.7)$ & $20(16.5)$ & \\
\hline $\begin{array}{l}\text { US } \\
\text { microcalcifications }\end{array}$ & & & 0.171 & & & 0.354 & & & 0.003 & & & & $<0.001$ \\
\hline Negative & $22(16.8)$ & $61(46.6)$ & & $29(22.1)$ & $54(41.2)$ & & 47 (35.9) & $36(27.5)$ & & $33(27.3)$ & $31(25.6)$ & $10(8.3)$ & \\
\hline Positive & $19(14.5)$ & $29(22.1)$ & & $21(16.0)$ & $27(20.6)$ & & $14(10.7)$ & $34(26.0)$ & & $9(7.4)$ & $13(10.7)$ & $25(20.7)$ & \\
\hline US ductal change & & & 0.608 & & & 0.463 & & & 0.636 & & & & 0.792 \\
\hline Negative & $36(27.5)$ & $74(56.5)$ & & $44(33.6)$ & $66(50.4)$ & & $50(38.2)$ & $60(45.8)$ & & $36(29.8)$ & 36 (29.8) & $28(23.1)$ & \\
\hline Positive & $5(3.8)$ & $16(12.2)$ & & $6(4.6)$ & $15(11.5)$ & & $11(8.4)$ & $10(7.6)$ & & $6(5.0)$ & $8(6.6)$ & $7(5.8)$ & \\
\hline
\end{tabular}

Values are presented as number (\%).

DCIS, ductal carcinoma in situ; ER, estrogen receptor; PR, progesterone receptor; HER2, human epidermal growth factor receptor; US, ultrasonography.

a significant correlation with a high nuclear grade and comedonecrosis. In previous studies of the radiologic and pathologic findings of pure DCIS, microcalcifications on mammography and ultrasonography have been reported to be associated with poor pathologic prognostic factors, such as a high nuclear grade or comedonecrosis $[10,16,33]$. In the ultrasonographic findings of pure DCIS, microcalcifications have been reported to be more common in high-nuclear-grade lesions than in low-nuclear-grade lesions [12]. They have also been more frequently reported in cases with comedonecrosis than in cases without comedonecrosis [10].

Biological markers such as ER, PR, HER2, and the Ki-67 index in pure DCIS cases were also analyzed in our study. Unlike previous studies, our study compared the ultrasonographic findings of pure DCIS with immunologic findings that could predict the prognosis of the lesion. Microcalcifications found on ultrasonography showed a statistically significant correlation with HER2 positivity or an increased Ki-67 index. These results suggest that the ultrasonographic imaging of DCIS may provide meaningful information for predicting its prognosis based on pathologic findings and some biological markers. Previous studies have reported that frequent local recurrence of DCIS was associated with ER negativity, PR negativity, HER2 positivity, and an elevated Ki-67 index [23]. It has been suggested that HER2 and the Ki-67 index might be significant prognostic factors for predicting recurrence after conservative surgery for DCIS [34]. Yao et al. [35] reported that a high Ki-67 index with HER2 positivity in DCIS in the presence of microinvasion was correlated with microcalcifications seen on ultrasonography. 
This study has several limitations. First, the number of patients included for screening and the number of patients with symptoms were similar. Additionally, selection bias may have been present because patients with unavailable ultrasonographic findings before biopsy were excluded. Third, the static ultrasonographic findings of pure DCIS were analyzed retrospectively. In addition, although ultrasonographic findings were analyzed jointly with pathologic and molecular biological markers of pure DCIS, mammography findings were not analyzed. Finally, ultrasonography is not a standard technique for evaluating microcalcifications. Therefore, the detection rate of microcalcifications may have been lower than the detection rate that is possible using mammography. Further studies are needed to determine the correlation of microcalcifications between ultrasonography and mammography.

In conclusion, the most common finding of pure DCIS was a mass with an irregularly shaped, indistinct margin and hypoechogenicity. Ultrasonographic microcalcifications and ductal changes were associated with non-mass lesions, which were correlated with poor prognostic factors such as a high nuclear grade, comedonecrosis, HER2 positivity, and an increased Ki-67 index. Ultrasonographic nonmass lesions with microcalcifications require careful management.

ORCID: Hwajin Cha: http://orcid.org/0000-0002-6292-0350; Yun-Woo Chang: http://orcid.org/0000-0001-9704-8112; Eun Ji Lee: http://orcid.org/0000-00024860-2495; Ji Young Hwang: http://orcid.org/0000-0002-3070-4880; Hyun Joo Kim: http://orcid.org/0000-0001-5386-1881; Eun Hye Lee: http://orcid.org/0000-00028773-700X; Jung Kyu Ryu: http://orcid.org/0000-0001-8195-0785

\section{Conflict of Interest}

No potential conflict of interest relevant to this article was reported.

\section{Acknowledgments}

This work was supported by Soonchunhyang University Research Fund.

\section{References}

1. Page DL, Dupont WD. Anatomic indicators (histologic and cytologic) of increased breast cancer risk. Breast Cancer Res Treat 1993;28:157-166.

2. Dershaw DD, Abramson A, Kinne DW. Ductal carcinoma in situ: mammographic findings and clinical implications. Radiology 1989;170:411-415.

3. Schnitt SJ, Silen W, Sadowsky NL, Connolly JL, Harris JR. Ductal carcinoma in situ (intraductal carcinoma) of the breast. N Engl J Med 1988;318:898-903.

4. Stomper PC, Connolly JL. Ductal carcinoma in situ of the breast: correlation between mammographic calcification and tumor subtype. AJR Am J Roentgenol 1992;159:483-485.

5. Virnig BA, Tuttle TM, Shamliyan T, Kane RL. Ductal carcinoma in situ of the breast: a systematic review of incidence, treatment, and outcomes. J Natl Cancer Inst 2010;102:170-178.

6. Allred DC. Ductal carcinoma in situ: terminology, classification, and natural history. J Natl Cancer Inst Monogr 2010;2010:134-138.

7. Burstein HJ, Polyak K, Wong JS, Lester SC, Kaelin CM. Ductal carcinoma in situ of the breast. N Engl J Med 2004;350:14301441.

8. Erbas B, Provenzano E, Armes J, Gertig D. The natural history of ductal carcinoma in situ of the breast: a review. Breast Cancer Res Treat 2006;97:135-144.

9. Evans A, Pinder S, Wilson R, Sibbering M, Poller D, Elston C, et al. Ductal carcinoma in situ of the breast: correlation between mammographic and pathologic findings. AJR Am J Roentgenol 1994;162:1307-1311.

10. Scoggins ME, Fox PS, Kuerer HM, Rauch GM, Benveniste AP, Park YM, et al. Correlation between sonographic findings and clinicopathologic and biologic features of pure ductal carcinoma in situ in 691 patients. AJR Am J Roentgenol 2015;204:878-888.

11. Wang LC, Sullivan M, Du H, Feldman MI, Mendelson EB. US appearance of ductal carcinoma in situ. Radiographics 2013:33:213-228.

12. Park JS, Park YM, Kim EK, Kim SJ, Han SS, Lee SJ, et al. Sonographic findings of high-grade and non-high-grade ductal carcinoma in situ of the breast. J Ultrasound Med 2010;29:1687-1697.

13. Perou CM, Sorlie T, Eisen MB, van de Rijn M, Jeffrey SS, Rees $\mathrm{CA}$, et al. Molecular portraits of human breast tumours. Nature 2000;406:747-752.

14. Cho KR, Seo BK, Kim CH, Whang KW, Kim YH, Kim BH, et al. Noncalcified ductal carcinoma in situ: ultrasound and mammographic findings correlated with histological findings. Yonsei Med J 2008:49:103-110.

15. Izumori A, Takebe K, Sato A. Ultrasound findings and histological features of ductal carcinoma in situ detected by ultrasound examination alone. Breast Cancer 2010;17:136-141.

16. Kim JH, Ko ES, Kim DY, Han H, Sohn JH, Choe DH. Noncalcified ductal carcinoma in situ: imaging and histologic findings in 36 tumors. J Ultrasound Med 2009;28:903-910.

17. Moon WK, Myung JS, Lee YJ, Park IA, Noh DY, Im JG. US of ductal carcinoma in situ. Radiographics 2002;22:269-280.

18. Shin HJ, Kim HH, Kim SM, Kwon GY, Gong G, Cho OK. Screeningdetected and symptomatic ductal carcinoma in situ: differences in the sonographic and pathologic features. AJR Am J Roentgenol 2008;190:516-525.

19. Nofech-Mozes S, Spayne J, Rakovitch E, Hanna W. Prognostic and predictive molecular markers in DCIS: a review. Adv Anat Pathol 2005; 12:256-264. 
20. Bijker N, Peterse JL, Duchateau L, Julien JP, Fentiman IS, Duval $\mathrm{C}$, et al. Risk factors for recurrence and metastasis after breastconserving therapy for ductal carcinoma-in-situ: analysis of European Organization for Research and Treatment of Cancer Trial 10853. J Clin Oncol 2001;19:2263-2271.

21. Lari SA, Kuerer HM. Biological markers in DCIS and risk of breast recurrence: a systematic review. J Cancer 2011;2:232-261.

22. Davis JE, Nemesure B, Mehmood S, Nayi V, Burke S, Brzostek $\mathrm{SR}$, et al. Her2 and Ki67 biomarkers predict recurrence of ductal carcinoma in situ. Appl Immunohistochem Mol Morphol 2016;24:20-25.

23. Irshad A, Leddy R, Pisano E, Baker N, Lewis M, Ackerman S, et al. Assessing the role of ultrasound in predicting the biological behavior of breast cancer. AJR Am J Roentgenol 2013;200:284290.

24. Allred DC, Anderson SJ, Paik S, Wickerham DL, Nagtegaal ID, Swain $S M$, et al. Adjuvant tamoxifen reduces subsequent breast cancer in women with estrogen receptor-positive ductal carcinoma in situ: a study based on NSABP protocol B-24. J Clin Oncol 2012;30:12681273.

25. Polyak K. Molecular markers for the diagnosis and management of ductal carcinoma in situ. J Natl Cancer Inst Monogr 2010;2010:210-213.

26. Gwak YJ, Kim HJ, Kwak JY, Lee SK, Shin KM, Lee HJ, et al. Ultrasonographic detection and characterization of asymptomatic ductal carcinoma in situ with histopathologic correlation. Acta Radiol 2011;52:364-371.

27. Mendelson EB, Bohm-Velez M, Berg WA, Whitman GJ, Feldman MI, Madjar H, et al. ACR BI-RADS ultrasound. In: D'Orsi CJ, Sickles EA, Mendelson EB, Morris EA, eds. ACR BI-RADS Atlas: Breast Imaging Reporting and Data System. Reston, VA: American College of Radiology, 2013;1-173.

28. Ueno E, Endo T, Kubota $M$, Kawauchi $A$, Kato $Y$, Konishi $Y$, et al.
Draft JSUM diagnostic guidelines for mass image-forming lesions. In: Ueno E, Shiina T, Kubota M, Sawai K, eds. Research and development in breast ultrasound. Tokyo: Springer-Verlag, 2005;7688.

29. Hammond ME, Hayes DF, Wolff AC, Mangu PB, Temin S. American Society of Clinical Oncology/College of American Pathologists guideline recommendations for immunohistochemical testing of estrogen and progesterone receptors in breast cancer. J Oncol Pract 2010;6:195-197.

30. Ohlschlegel C, Zahel K, Kradolfer D, Hell M, Jochum W. HER2 genetic heterogeneity in breast carcinoma. J Clin Pathol 2011;64:1112-1116.

31. Bae MS, Moon WK, Chang JM, Cho N, Park SY, Won JK, et al. Mammographic features of calcifications in DCIS: correlation with oestrogen receptor and human epidermal growth factor receptor 2 status. Eur Radiol 2013;23:2072-2078.

32. Goldhirsch A, Winer EP, Coates AS, Gelber RD, Piccart-Gebhart M, Thurlimann $B$, et al. Personalizing the treatment of women with early breast cancer: highlights of the St Gallen International Expert Consensus on the Primary Therapy of Early Breast Cancer 2013. Ann Oncol 2013;24:2206-2223.

33. Mun HS, Shin HJ, Kim HH, Cha JH, Kim H. Screening-detected calcified and non-calcified ductal carcinoma in situ: differences in the imaging and histopathological features. Clin Radiol 2013;68:e27-e35.

34. Rakovitch E, Nofech-Mozes S, Hanna W, Narod S, Thiruchelvam D, Saskin $R$, et al. HER2/neu and Ki-67 expression predict noninvasive recurrence following breast-conserving therapy for ductal carcinoma in situ. Br J Cancer 2012;106:1160-1165.

35. Yao JJ, Zhan WW, Chen $M$, Zhang XX, Zhu Y, Fei XC, et al. Sonographic features of ductal carcinoma in situ of the breast with microinvasion: correlation with clinicopathologic findings and biomarkers. J Ultrasound Med 2015;34:1761-1768. 